\title{
Penilaian Kualitas Tanah Kebun Kakao Rakyat Menggunakan Kriteria Minimum Data Set (MDS) dan Korelasinya dengan Produksi Kakao
}

(Soil Quality Assessment of Community Cacao Farms Using Minimum Data Set (MDS)

Criteria and Its Correlation with Cacao Production)

\author{
Ayu Azzuhra' ${ }^{1}$ Zainabun ${ }^{1}$, Abubakar Karim ${ }^{1 *}$ \\ ${ }^{1}$ Program Studi Ilmu Tanah, Fakultas Pertanian, Universitas Syiah Kuala \\ *Corresponding author: karim.abubakar@unsyiah.ac.id
}

\begin{abstract}
Abstrak. Provinsi Aceh secara agroekosistem berpotensi besar dalam pengembangan kakao. Salah satu sentra produksi kakao di Aceh adalah Kabupaten Pidie Jaya. Luas kebun kakao rakyat di Kabupaten Pidie Jaya pada tahun 2017 adalah 13.404 ha dengan produksi 4.349 ton per tahun. Kualitas tanah sangat mempengaruhi pertumbuhan kakao. Tujuan penelitian adalah menganalisis kualitas tanah kebun kakao rakyat menggunakan nilai soil quality rating $(\mathrm{SQR})$ dan hubungannya dengan produksi kakao rakyat di Kabupaten Pidie Jaya. Bahan yang digunakan adalah sampel tanah utuh dan tanah tidak utuh. Data primer merupakan data hasil pengamatan lapangan, baik data maupun data produksi. Analisis sifat-sifat fisika tanah (ER), sifat-sifat kimia tanah (TP), dan sifat-sifat biologi tanah (OM), disesuaikan dengan faktor pembatas dan bobot relatif, maka diperoleh hasil kualitas tanah. Kualitas tanah ditentukan dengan menghitung nilai Soil Quality Rating (SQR), yaitu kelas kualitas tanah yang dihitung berdasarkan penjumlahan bobot nilai tiap indikator kualitas tanah (Lal, 1994). Berdasarkan hasil penjumlahan bobot nilai tiap indikator kualitas tanah, lalu dibandingkan dengan standar kualitas tanah yang disusun Lal (1994) maka diperoleh kualitas tanah. Kualitas tanah kebun kakao rakyat dari kedelapan satuan lahan yang ada di 4 kecamatan di Kabupaten Pidie Jaya termasuk kedalam kriteria kualitas tanah sedang, buruk dan sangat buruk dan produksi kakao rakyat dalam kategori rendah yaitu 3,7-11,2 ton/ha.
\end{abstract}

Kata kunci: Kualitas tanah, kebun kakao rakyat, soil quality rating, produksi.

\begin{abstract}
Aceh Province as an agro-ecosystem has great potential in cocoa development. One of the cocoa production centers in Aceh is Pidie Jaya Regency. The area of community cocoa plantations in Pidie Jaya Regency in 2017 was 13,404 ha with a production of 4,349 tons per year. Soil quality greatly affects cocoa growth. The purpose of the study was to analyze the soil quality of the community's cocoa plantations using the value of the soil quality rating (SQR) and its relations with the cocoa production of the people in Pidie Jaya Regency. The materials used were intact soil samples and incomplete soil samples. Primary data is data from field observations, both data and production data. Analysis of soil physical properties (ER), soil chemical properties (TP), and soil biological properties (OM), adjusted for limiting factors and relative weights, obtained soil quality results. Soil quality is determined by calculating the value of the Soil Quality Rating (SQR), namely the soil quality class which is calculated based on the sum of the weight values of each soil quality indicator (Lal, 1994). Based on the results of the sum of the weight values of each soil quality indicator, then compared with the soil quality standards compiled by Lal (1994), the soil quality is obtained. The soil quality of the people's cocoa plantations from the eight land units in 4 sub-districts in Pidie Jaya Regency is included in the criteria for medium, poor and very poor soil quality and the community's cocoa production is in the low category, namely 3.7-11.2 tons/ha.
\end{abstract}

Keywords: Soil Quality, People's Cocoa Plantation, Soil Quality Rating, Production.

\section{PENDAHULUAN}

Tanaman kakao (Theobroma cacao) berasal dari kawasan Amerika Selatan, tepatnya dari lembah Amazon dan Venezuela. Tanaman kakao, pertama masuk ke Indonesia melalui Filipina ke Pulau Sulawesi pada abad ke-16. Pusat produksi kakao di Indonesia adalah kepulauan Sulawesi, yaitu Sulawesi Tengah, Sulawesi Tenggara, Sulawesi Selatan, dan Sulawesi Barat. Provinsi Aceh secara agroekosistem berpotensi besar dalam pengembangan kakao. Selain mempunyai lahan seluas 101.230 hektar yang dapat dimanfaatkan dan umumnya diusahakan masyarakat. Selanjutnya, wilayah sentra produksi kakao di Provinsi Aceh terdapat di Kabupaten Aceh Tenggara, Pidie, Pidie Jaya, Bireuen, Aceh Utara, dan Aceh Timur. Luas 
kebun kakao Aceh telah mencapai 101.230 ha dengan produksi 39.296,00 ton per tahun. Kebun kakao ini sebagian besar diusahakan oleh perkebunan rakyat (BPS Aceh, 2017). Data Badan Statistik Aceh tahun 2017 menunjukan, areal tanaman kakao di Kabupaten Pidie Jaya seluas 13. 404,00 ha dengan produksi 4.349,00 ton per tahun dengan produktivitasnya sebesar 324,5 ton per hektar. Areal tersebut tersebar di delapan kecamatan, yakni Trienggadeng, Meureudu, Bandar Dua, Ulim, Panteraja, Jangka Buya, Meurah Dua, dan Bandar Baru. Luasnya pengembangan kebun kakao rakyat ini di Kabupaten Pidie Jaya, telah mendorong kabupaten ini sebagai salah satu sentra produksi kakao di Provinsi Aceh.

Kualitas tanah merupakan komponen fisik, kimia dan biologi tanah serta interaksinya. Kualitas tanah menjadi kapasitas spesifik suatu tanah untuk berfungsi secara alami dan/atau dalam batasan-batasan ekosistem yang dikelola untuk menopang produktivitas hewan dan tumbuhan, memelihara atau meningkatkan kualitas udara dan air, serta mendukung tempat tinggal dan kesehatan manusia (Larson dan Pierce, 1994). Kualitas tanah yang baik akan mendukung kerja fungsi tanah sebagai media pertumbuhan tanaman, mengatur dan membagi aliran air dan menyangga lingkungan yang baik pula. Kualitas tanah sangat mempengaruhi pertumbuhan kakao, apabila suatu kondisi tanah yang memiliki kualitas baik maka pertumbuhan tanaman kakao menjadi lebih subur sehingga produktivitas dan produksi kakao meningkat. Penelitian ini bertujuan untuk menganalisis kualitas tanah kebun kakao rakyat dai hubungannya dengan produksi dan produktivitas kakao di Kabupaten Pidie Jaya.

\section{METODE PENELITIAN}

\section{Tempat dan Waktu}

Penelitian ini dilaksanakan di Kabupaten Pidie Jaya. Ada 4 kecamatan yang menjadi target penilaian penelitian ini, yaitu Kecamatan Bandar Dua, Meurah Dua, Ulim dan, Bandar Baru. Analisis Sifat-sifat tanah dilakukan di Laboratorium Fisika Tanah, Laboratorium Biologi Tanah dan Laboratorium Tanah dan Tanaman di Lingkungan Fakultas Pertanian, Universitas Syiah Kuala dan Balai Pengkajian Teknologi Pertanian. Penelitian berlangsung sejak Oktober hingga Desember 2020.

\section{Alat dan Bahan}

Alat-alat yang akan digunakan dalam penelitian ini adalah aplikasi pengolahan data, berupa Software ArcGIS Dekstop 10.5, dan MS. Excel, bor tanah, ring sampel, pisau lapang, kantong plastik, GPS, gelas ukur, gelas erlenmeyer, mortar dan alue, timbangan analitik, labu destilasi, buret dan lainnya. Bahan sampel tanah utuh dan tanah tidak utuh, data primer, data sekunder meliputi data letak geografis, peta administrasi, kemiringan lereng, jenis tanah, masing-masing skala $1: 60.000$, serta beberapa jenis larutan kimia yang digunakan untuk keperluan analisis sifat-sifat tanah di laboratorium.

\section{Metode}

Penelitian ini menggunakan metode survai tanah dan analisis deskriptif, yaitu melalui kegiatan observasi lapangan dan analisis laboratorium. Kegiatan survai lapangan dilakukan untuk mendapatkan data primer berupa kondisi biofisik wilayah dan karakteristik fisika, kimia, dan biologi tanah. Pengamatan data morfologi lahan dan pengambilan contoh tanah dilakukan 
secara acak/random (random sampling) pada masing-masing satuan lahan (SL) yang dibentuk berdasarkan jenis tanah, lereng, dan kebun kakao.

\section{Persiapan}

Kegiatan yang dilakukan pada tahap ini survei awal untuk mengurus perizinan lokasi, penyiapan alat dan bahan, pengumpulan data primer dan sekunder, pembentukan satuan lahan, dan menentukan titik sampel awal.

\section{Pembentukan Tapak Pengamatan}

Tapak pengamatan dibentuk berdasarkan perbedaan jenis tanah dan kemiringan lereng. Ada 4 kelas jenis tanah yaitu Inceptisol, Ultisol, Entisol dan Andisol dengan 5 kelas kemiringan lereng yaitu $0-8 \%, 8-15 \%, 15-25 \%, 25-45 \%$ dan $>45 \%$. Ada sebanyak 17 satuan lahan yang terbentuk dan 8 satuan lahan yang dijadikan tapak pengamatan.

\section{Survei Lapangan}

Survei lapang ditujukan untuk mengecek kebenaran dan batas delineasi satuan lahan (SL - tapak pengamatan) dan sekaligus penentuan titik pengambilan contoh tanah pada masingmasing tapak pengamatan.

\section{Pengambilan Sampel Tanah}

Tapak pengamatan dibentuk berdasarkan perbedaan jenis tanah dan kemiringan lereng. Ada 4 kelas jenis tanah yaitu Inceptisol, Ultisol, Entisol dan Andisol dengan 5 kelas kemiringan lereng yaitu $0-8 \%, 8-15 \%, 15-25 \%, 25-45 \%$ dan $>45 \%$, sehingga ada 20 satuan lahan (SL-tapak pengamatan). Namun hasil tumpang tindih kedua peta ini hanya diperoleh sebanyak 17 satuan lahan. Ada 8 satuan lahan yang dijadikan tapak pengamatan pengambilan contoh tanah. Pengambilan contoh tanah utuh diambil menggunakan ring sampel pada top soil di kebun kakao dan pengambilan contoh tanah tidak utuh diambil menggunakan bor tanah dengan kedalaman 0-20 cm. Contoh tanah diambil secara acak pada satuan lahan terpilih 3 titik pengamatan. Selanjutnya untuk analisis sifat-sifat kimia dan biologi tanah (sampel tanah terganggu) dijadikan contoh tanah komposit dari 3 titik pengamatan pada setiap satu satuan lahan.

\section{Data Produksi}

Data produksi didapatkan melalui wawancara dengan pemilik kebun. Data produksi yang didapat berupa produksi kakao per tanaman, jarak tanam kakao, luas kebun dan harga kakao.

\section{Analisis Tanah}

Peubah sifat-sifat tanah untuk keperluan analisis kualitas tanah menggunakan kriteria minimum data set mengacu kepada kriteria yang disusun Lal (1994). Peubah sifat-sifat tanah dimaksud; sifat fisik tanah meliputi tekstur tanah, bulk density, porositas dan kadar air tanah; sifat kimia tanah meliputi C-Organik, pH, KTK, P-tersedia, K-dipertukarkan, dan N-total tanah; dan sifat biologi tanah terdiri dari respirasi dan dan total mikroorganisme tanah.

\section{Pengamatan Deskripsi Lahan}


Deskripsi lahan dilakukan dengan tujuan untuk mengetahui kondisi fisik tanaman dan kebun kakao yang menjadi objek pengamatan. Pengumpulan data produksi dilakukan melalui wawancara dengan petani pemilik kebun kakao sebanyak 5-7 responden per satuan lahan, serta observasi langsung di lapangan. Secara umum peubah pendukung produksi yang diamati meliputi luas areal kebun kakao, asal bahan tanam, dan tahun tanam (umur tanaman kakao). Teknik budidaya tanaman kakao, meliputi pemupukan, pemangkasan, pengelolaan seresah, pengendalian gulma, hama dan penyakit tanaman, jenis tanaman penaung dan pengelolaannya, dan produksi kakao.

\section{Analisis Data}

Hasil analisis contoh tanah digunakan untuk penilaian kualitas tanah. Langkah awal dilakukan pengkriterian faktor pembatas dan pembobotan relatif indikator kualitas tanah berdasarkan (Lal, 1994). Kualitas tanah ditentukan dengan menghitung nilai soil quality rating (SQR), yaitu kelas kualitas tanah yang dihitung berdasarkan penjumlahan bobot nilai tiap indikator kualitas tanah. Nilai SQR selanjutnya dibandingkan dengan kriteria kualitas tanah yang mengacu dengan Lal (1994).

\section{HASIL DAN PEMBAHASAN}

\section{Karakteristik Satuan Lahan}

Deskripsi tapak pengamatan ke-8 satuan lahan didapatkan dari hasil pengamatan dan wawancara dengan petani pemilik kebun kakao (Tabel 1).

Tabel 1. Deskripsi Tapak Pengamatan Delapan Satuan Lahan Kebun Kakao Rakyat di Kabupaten Pidie Jaya

\begin{tabular}{|c|c|c|c|c|c|c|c|c|c|}
\hline \multirow[b]{2}{*}{ No. } & \multirow{2}{*}{$\begin{array}{c}\text { Deskripsi Satuan } \\
\text { Lahan }\end{array}$} & \multicolumn{8}{|c|}{ Satuan Lahan } \\
\hline & & SPL 1 & SPL 4 & SPL 5 & SPL 7 & SPL 9 & SPL 13 & SPL 14 & SPL 16 \\
\hline 1. & Jenis Tanah & Inc. & Ult. & Inc. & Ult. & Inc. & Inc. & Ult. & Inc. \\
\hline 2. & Lereng (\%) & $0-8$ & $0-8$ & $8-15$ & $8-15$ & $8-15$ & $15-25$ & $15-25$ & $25-45$ \\
\hline 3. & Luas Kebun (ha) & 2,0 & 2,0 & 1,0 & 2,0 & 2,0 & 1,0 & 1,0 & 2,5 \\
\hline 4. & Jenis Kakao & $\mathrm{F} 1$ & $\mathrm{~F} 1$ & $\mathrm{~F} 1$ & $\mathrm{~F} 1$ & $\mathrm{~F} 1$ & $\mathrm{~F} 1$ & $\mathrm{~F} 1$ & $\mathrm{~F} 1$ \\
\hline 5. & $\begin{array}{l}\text { Umur } \\
\text { (tahun) }\end{array}$ & 13 & 15 & 19 & 19 & 13 & 15 & 15 & 15 \\
\hline 6. & Jarak Tanam & $3 \times 3$ & $3 \times 3$ & $4 \times 2$ & $4 \times 2$ & $4 \times 2$ & $3 \times 3$ & $3 \times 3$ & $3 \times 3$ \\
\hline 7. & Naungan & Pinang & $\begin{array}{l}\text { Durian, } \\
\text { Pala, } \\
\text { Pinang. }\end{array}$ & Pinang & $\begin{array}{l}\text { Mang., } \\
\text { Pala }\end{array}$ & Pinang & $\begin{array}{l}\text { Durian } \\
\text { Pala, } \\
\text { Pinang }\end{array}$ & $\begin{array}{l}\text { Durian } \\
\text { Pala, } \\
\text { Pinang }\end{array}$ & Mang. \\
\hline 8. & Pemupukan & NPK & NPK & NPK & NPK & NPK & NPK & NPK & NPK \\
\hline 9. & $\begin{array}{l}\text { Pengendalian hama } \\
\text { dan Penyakit }\end{array}$ & ta & ta & ta & ta & ta & ta & ta & ta \\
\hline 10. & $\begin{array}{l}\text { Produksi } \\
\text { (kg/pohon) }\end{array}$ & 4,5 & 4,0 & 3,0 & 3,0 & 4,5 & 4,0 & 4,0 & 4,0 \\
\hline
\end{tabular}

Keterangan: $\quad$ Inc. = Inceptisol, Ult. = Ultisol; Mang = manggis; NPK = pupuk NPK; ta = tidak ada.

\section{Produksi Kakao dari Delapan Satuan Lahan}

Produksi delapan satuan lahan beragam, produksi per pohon dan produksi per hektar. Produksi kakao perpohon pada SPL 5 dan SPL 7 yaitu 3,0 kg perpohon, pada SPL 4, 13, 14 dan 16 produksi perpohon 4,0 kg perpohon dan SPL 1 dan SPL 9 produksinya 4,5 kg perpohon. Produktivitas pada SPL 5 dan 7 yaitu 3,7 ton/ha, SPL 4, 13, 14 dan 16 produktivitasnya 4,4 
ton/ha. Produktivitas pada SPL 1 5,0 ton/ha dan SPL 5,6 ton/ha. Jumlah batang kakao perhektar SPL 1,4,13,14 dan 16 yaitu 1.111 batang dan SPL 5,7,9 memiliki 1.250 batang.

\section{Analisis Tanah}

Hasil analisis sifat-sifat fisika tanah (Tabel 2), kimia tanah (Tabel 3), dan biologi tanah (Tabel 4) digunakan untuk penilaian kualitas tanah berdasarkan nilai SQR disajikan.

\section{Sifat Fisik Tanah}

Tabel 2 menunjukkan hasil analisis bobot volume (bulk density), kadar air, dan tekstur tanah. Bulk density tanah pada SPL 1, SPL 4, SPL 5, SPL 7, SPL 9, SPL 13, SPL 14 dan SPL 16 tergolong tanpa faktor pembatas. Nilai bulk density menunjukan tidak diperlukan pengelolaan lanjut karena bulk density tanah sudah sesuai, tidak ada kompaksi. Keseluruhan tapak pengamatan menunjukkan nilai bulk density tinggi. tanah yang memiliki nilai bulk density tinggi merupakan tanah yang berporositas baik sehingga mudah akar untuk berpenetrasi didalam tanah (Hardjowigeno, 2007).

Porositas tanah SPL 1, SPL 4, SPL 5, SPL 7, SPL 9, SPL 13, SPL 14, dan SPL 16 tergolong tanpa faktor pembatas (Tabel 2). Nilai porositas tanah semua tapak pengamatan sangat baik, dimana tidak diperlukannya pengelolaan lanjutan. Nilai porositas baik disebabkan nilai bulk density yang baik. Sejalan dengan pendapat Liyanda et. Al. (2012) sifat fisik yang baik adalah jika mampu menahan air dengan baik, lebih tepatnya memiliki peredaran udara (aerasi) dan penyediaan air tanah yang baik bagi pertumbuhan dan pernapasan (respirasi) akar.

Kadar air tanah pada SPL 1, SPL 4, SPL 5, SPL 7, SPL 14, dan SPL 16 tergolong dengan faktor pembatas sedang (Tabel 2). Kadar air tanah SPL 9 dan SPL 13 tanpa faktor pembatas dan faktor pembatas ringan dengan nilai 35,14\% dan 23,46\%. Kandungan kadar air pada kebun kakao lokasi penelitian termasuk tinggi karena teksur tanah liat, dimana teksur liat dapat memegang air dalam tanah sehingga kadar airnya tinggi. Sejalan dengan pendapat pendapat Haridjaja, et al. (2013)

Tekstur tanah SPL 1, SPL 4, SPL 5, SPL 9, SPL 13, SPL 14, dan SPL 16 bertekstur liat dan SPL 7 liat berdebu. Tekstur tanah relatifnya tidak dapat berubah.

\section{Sifat Kimia Tanah}

Tabel 3 menunjukkan hasil analisis pH, C-organik, KTK, KB, N-total, P-tersedia dan Ktersedia. Hasil analisis sifat kimia tanah disajikan pada Tabel 3. Hasil analisis pH contoh SPL 1, SPL 5, SPL SPL 7, SPL 9, termasuk kedalam faktor pembatas berat. Hal ini disebabkan pada tersebut tanah kebun kakao yang sudah sudah relatif lama digunakan, umur tanaman kakao berkisar 13-19 tahun dan tidak dikelola dengan baik dan bahkan dibiarkan terbengkalai oleh petani kakao. Sejalan dengan pendapat (Hardjowigeno, 2007) Reaksi (pH) tanah penting sebagai penciri mudah tidaknya unsur-unsur hara diserap tanaman.

Kandungan C-organik contoh tanah SPL 1, SPL 4, SPL 5, SPL 7, SPL 9, SPL 13, SPL 14, dan SPL 16 termasuk kedalam faktor pembatas sedang. Hal ini disebabkan tanah kebun kakao seluruh SPL dipenuhi daun-daun dan serasah tanaman kakao maupun tanaman naungannya tidak dipindahkan, tidak dibersihkan dan dan tidak dibakar. Kandungan bahan organik merupakan salah satu indikator tingkat kesuburan tanah (Susanto, 2005).

Tabel 2. Hasil Analisis Sifat Fisika Tanah (Bulk Density, Kadar Air, dan Tekstur Tanah) Tapak Pengamatan

\begin{tabular}{cccccccccc} 
Tapak & BD & Faktor & Bobot & KA & Faktor & Bobot & Porositas & Faktor & Bobot \\
Pengamatan & $\left(\mathrm{g} / \mathrm{cm}^{3}\right)$ & Pembatas & Relatif & $(\%)$ & Pembatas & Relatif & $(\%)$ & Pembatas & Relatif \\
\hline
\end{tabular}




\begin{tabular}{|c|c|c|c|c|c|c|c|c|c|}
\hline SPL 1 & 0,71 & Tanpa & 1 & 14,94 & Sedang & 3 & 45,96 & Tanpa & 1 \\
\hline SPL 4 & 1,20 & Tanpa & 1 & 17,65 & Sedang & 3 & 44,19 & Tanpa & 1 \\
\hline SPL 5 & 0,86 & Tanpa & 1 & 19,05 & Sedang & 3 & 36,46 & Tanpa & 1 \\
\hline SPL 7 & 0,45 & Tanpa & 1 & 17,65 & Sedang & 3 & 58,23 & Tanpa & 1 \\
\hline SPL 9 & 0,61 & Tanpa & 1 & 35,14 & Tanpa & 1 & 46,58 & Tanpa & 1 \\
\hline SPL 13 & 1,03 & Tanpa & 1 & 23,46 & Ringan & 2 & 37,50 & Tanpa & 1 \\
\hline SPL 15 & 1,15 & Tanpa & 1 & 17,65 & Sedang & 3 & 38,79 & Tanpa & 1 \\
\hline SPL 16 & 0,57 & Tanpa & 1 & 17,65 & Sedang & 3 & 45,67 & Tanpa & 1 \\
\hline
\end{tabular}

Keterangan: $\mathrm{BD}=$ bulk density, $\mathrm{KA}=$ kadar air, $\mathrm{Li}=$ liat, $\mathrm{LiD}=$ Liat berdebu

Tabel 3. Hasil Analisis Sifat Kimia Tanah (pH, C-organik, N-total dan P-Tersedia Tanah) Tapak Pengamatan

\begin{tabular}{|c|c|c|c|c|c|c|c|c|c|}
\hline $\begin{array}{c}\text { Tapak } \\
\text { Pengamatan }\end{array}$ & pH & $\begin{array}{c}\text { Faktor } \\
\text { Pembatas }\end{array}$ & $\begin{array}{l}\text { Bobot } \\
\text { Relatif }\end{array}$ & C-Org & $\begin{array}{c}\text { Faktor } \\
\text { Pembatas }\end{array}$ & $\begin{array}{c}\text { Bobot } \\
\text { Relatif }\end{array}$ & N-total & $\begin{array}{c}\text { Faktor } \\
\text { Pembatas }\end{array}$ & $\begin{array}{l}\text { Bobot } \\
\text { Relatif }\end{array}$ \\
\hline SPL 1 & 5,28 & Berat & 4 & 1,91 & Sedang & 3 & 0,21 & Sedang & 3 \\
\hline SPL 4 & 6,76 & Tanpa & 1 & 1,98 & Sedang & 3 & 0,17 & Berat & 4 \\
\hline SPL 5 & 5,23 & Berat & 4 & 1,68 & Sedang & 3 & 0,14 & Berat & 4 \\
\hline SPL 7 & 5,12 & Berat & 4 & 1,54 & Sedang & 3 & 0,19 & Berat & 4 \\
\hline SPL 9 & 5,39 & Berat & 4 & 2,03 & Sedang & 3 & 0,20 & Berat & 4 \\
\hline SPL 13 & 5,67 & Sedang & 3 & 1,89 & Sedang & 3 & 0,23 & Sedang & 3 \\
\hline SPL 15 & 6,49 & Tanpa & 1 & 1,04 & Sedang & 3 & 0,16 & Berat & 4 \\
\hline SPL 16 & 5,4 & Sedang & 3 & 2,08 & Sedang & 3 & 0,20 & Berat & 4 \\
\hline
\end{tabular}

Tabel 4. Hasil Analisis Sifat Biologi Tanah (Respirasi tanah dan Total Mikroorganisme) dan Nilai SQR

\begin{tabular}{lcccc}
\hline $\begin{array}{c}\text { Tapak } \\
\text { Pengamatan }\end{array}$ & Respirasi & Faktor Pembatas & Bobot Relatif & $\begin{array}{c}\text { Total } \\
\text { Mikroorganisme }\end{array}$ \\
\hline SPL 1 & 2,65 & Tanpa & 1 & $38 \times 10^{4}$ \\
SPL 4 & 1,28 & Ringan & 2 & $34 \times 10^{4}$ \\
SPL 5 & 1,28 & Ringan & 2 & $73 \times 10^{4}$ \\
SPL 7 & 0,99 & Sedang & 3 & $47 \times 10^{4}$ \\
SPL 9 & 2,65 & Tanpa & 1 & $65 \times 10^{4}$ \\
SPL 13 & 2,48 & Tanpa & 1 & $87 \times 10^{4}$ \\
SPL 14 & 0,44 & Berat & 4 & $61 \times 10^{4}$ \\
SPL 16 & 1,98 & Ringan & 2 & Tanpa \\
\hline
\end{tabular}

Berdasarkan hasil analisis contoh tanah, N-total SPL 1 dan SPL 13 termasuk kedalam faktor pembatas sedang, sedangkan SPL 4, SPL 5, SPL 7, SPL 9, SPL 14 dan SPL 16 tergolong kedalam kelas rendah dengan faktor pembatas ekstrim. Rendahnya unsur N-total tanah di lokasi penelitian disebabkan oleh sifat $\mathrm{N}$ yang sangat mobil sehingga unsur $\mathrm{N}$ tercuci dan sangat mudah mengguap. Menurut Hardjowigeno (2003), hilangnya $\mathrm{N}$ dari tanah disebabkan karena digunakan oleh tanaman atau mikroorganisme, tercuci dan menguap

Kandungan P tersedia pada SPL 9 termasuk kelas tanpa faktor pembatas. SPL 1 termasuk kedalam faktor pembatas berat dan pada SPL 4, SPL5, SPL 7, SPL 13, SPL 14 dan SPL 16 termasuk kedalam faktor pembatas ekstrim. SPL 1 SPL 4, SPL 5, SPL 7, SPL 13 dan SPL 15 kandungan $\mathrm{P}$ tersedia rendah dan termasuk faktor pembatas ekstrim dikarenakan pada lokasi penelitian memiliki jenis tanah Ultisol dan Inceptisol, dimana jenis mengalami pelapukan sedang dan tercuci karena pengaruh musim basah dan kering yang sangat mempengaruhi tingkat pelapukan dan pencucian.

Kandungan K-dapat dipertukarkan pada SPL 1 dan SPL 9 tergolong tanpa faktor pembatas, SPL 13 tergolong faktor pembatas ringan. Ketersediaan K di dalam tanah tergantung kepada proses dan dinamika kalium dalam tanah terutama proses jerapan dan pelepasan. Apabila konsentrasi hara dalam larutan tanah meningkat (misal karena pemberian pupuk) maka hara segera dijerap oleh tanah menjadi bentuk tidak tersedia (sementara waktu), proses ini disebut sebagai jerapan (sorption) (Brady et al. 1984). 
Kandungan KTK pada SPL 1 dan SPL 9 termasuk tanpa faktor pembatas, dan SPL 4, 5, 7, 13, 14 termasuk faktor pembatas berat. Nilai KTK didapatkan dari nilai-nilai ion positif sejalan dengan pendapat Hardjowigeno (2007), kation adalah ion bermuatan positif seperti $\mathrm{Ca}^{++}, \mathrm{Mg}^{+}, \mathrm{K}^{+}, \mathrm{N}^{2+}, \mathrm{N}^{4+}, \mathrm{H}^{+}, \mathrm{Al}^{3+}$ dan sebagainya. Kation-kation yang telah dijerap oleh koloidkoloid tersebut sukar tercuci oleh air gravitasi, tetapi dapat diganti oleh kation lain yang terdapat dalam larutan tanah, ini yang disebut pertukaran kation.

Kejenuhan Basa (KB) pada SPL 9 termasuk faktor pembatas ringan, SPL 4, 7, 14, dan 16 faktor pembatas berat dan pada SPL 5 dan 13 termasuk faktor pembatas ekstrim Nilai KB adalah persentase dari KTK yang ditempati oleh kation-kation basa seperti kalium, kalsium, magnesium, dan natrium, jika nilai KTK rendah maka nilai KB juga rendah. Nilai $\mathrm{KB}$ berhubungan erat dengan $\mathrm{pH}$ dan tingkat kesuburan tanah. Kemasaman akan menurun dan kesuburan akan meningkat dengan meningkatnya KB. Laju pelepasan kation terjerab bagi tanaman tergantung pada tingkat kejenuhan basa tanah. Kejenuhan basa tanah berkisar $50 \%$ $80 \%$ tergolong mempunyai kesuburan sedang dan dikatakan tidak subur jika kurang dari $50 \%$ (Tan, 1991).

\section{Sifat Biologi Tanah}

Tabel 4 menunjukkan, respirasi tanah pada SPL 1, SPL 9 dan SPL 13 termasuk kedalam tanpa faktor pembatas. SPL 4, SPL 5 dan SPL 16 termasuk kedalam faktor pembatas ringan dengan nilai berturut-turut. SPL 7 termasuk kedalam faktor pembatas sedang, pada SPL 14 termasuk kedalam faktor pembatas berat. Hal ini disebabkan dari setiap kebun kakao adanya banyak tanaman lainnya dan banyaknya serasah dan dedaunan diatas tanah yang terdekomposisi sendiri sehingga bahan organik tanah tinggi. Bahan organik yang tinggi mempengaruhi aktivitas mikroorganisme tanah sehingga nilai respirasi tanah yang didapatkan dengan menghitung karbon (C) dalam tanah tinggi. Kondisi ini sejalan dengan pendapat Nurmegawati, et al. (2014).

Total mikroorganisme dihitung dengan banyaknya koloni dan jumlah pemipetan. Dimana banyaknya pemipetan tergantung dengan kesuburan tanah, pemipetan yang dilakukan lebih dari 4 kali pemipetan maka tanah tersebut dikatakan subur. Jumlah mikroorganisme tanah yang melimpah menggambarkan tingkat kesuburan tanah dan sifat tanah secara biologis (Irfan, 2014)

\section{Kualitas Tanah}

Penilaian kualitas tanah dilakukan dengan penambahan nilai indikator dari faktor pembatas pada sifat-sifat tanah yaitu sifat fisika (ER), kimia (TP) dan biologi (OM) tanah disesuaikan dengan Minimum data set (MDS) (Lal, 1994) (Tabel 2, 3, dan 4).

Perbedaan nilai SQR disebabkan oleh parameter dari sifat fisika, kimia dan biologi berbeda satu sama lain. Pada SPL 9 yaitu kebun kakao yang berada di Gampong Sagoe Langgieng, Kecamatan Bandar Baru tergolong kualitas tanah sedang dikarenakan pada hasil analisis laboratorium sifat kimianya tergolong kedalam faktor pembatas paling rendah dibanding dengan SPL yang lainnya. Sifat fisika dan biologinya hampir tanpa faktor pembatas, selain itu kebun kakao pada SPL 9 ini masih dilakukan pengelolaan tanah secara baik dan masih berproduksi. Sedangkan pada SPL 1, SPL 4, SPL 7, SPL 13, SPL 14, dan SPL 16 yang berada di sejumlah gampong dan kecamatan yang berbeda-beda berturut-turut yaitu Gampong Dayah Langgieng, Kecamatan Bandar Baru, Gampong Lhok Pusong, Kecamatan Bandar Dua, Gampong Paya Pisang Klat, Kecamatan Bandar Baru, Gampong Cot Seutui, Kecamatan Ulim, Gampong Lhok Pusong, Kecamatan Bandar Dua, dan Gampong Sarahmane, Kecamatan 
Meurah Dua, tergolong kualitas tanah buruk, dikarenakan hasil analisis laboratorium, baik sifat fisika tanah, maupun sifat kimia tanah termasuk kedalam faktor pembatas yang besar.

\section{Produksi Kakao}

Produktivitas kebun kakao dari kedelapan satuan lahan dihitung berdasarkan produksi kakao per tahun dibagi luas kebun masing-masing SPL. Produksi masing-masing SPL dihitung berdasarkan produksi per pohon dikali jumlah pohon per hektar dikali luas masing-masing SPL (Tabel 5).

Tabel 5. Hubungan antara Kualitas Tanah dan Produksi Kakao Rakyat di Kabupaten Pidie Jaya

\begin{tabular}{|l|l|c|c|c|c|c|}
\hline No. & $\begin{array}{c}\text { Contoh } \\
\text { Tanah }\end{array}$ & $\begin{array}{c}\text { Soil Quality } \\
\text { Rating (SQR) }\end{array}$ & $\begin{array}{c}\text { Deskripsi } \\
\text { Kualitas }\end{array}$ & $\begin{array}{c}\text { Luas Kebun } \\
\text { (ha) }\end{array}$ & $\begin{array}{c}\text { Produksi } \\
\text { (ton/tahun) }\end{array}$ & $\begin{array}{c}\text { Produktivitas } \\
\text { (ton/ha) }\end{array}$ \\
\hline 1. & SPL 1 & 31 & Buruk & 2 & 10 & 5,0 \\
\hline 2. & SPL 4 & 37 & Buruk & 2 & 8,8 & 4,4 \\
\hline 3. & SPL 5 & 42 & Sangat Buruk & 1 & 3,7 & 3,7 \\
\hline 4. & SPL 7 & 40 & Buruk & 2 & 7,4 & 3,7 \\
\hline 5. & SPL 9 & 29 & Sedang & 2 & 11,2 & 5,6 \\
\hline 6. & SPL 13 & 37 & Buruk & 1 & 4,4 & 4,4 \\
\hline 7. & SPL 14 & 39 & Buruk & 1 & 4,4 & 4,4 \\
\hline 8. & SPL 16 & 38 & Buruk & 2,5 & 11 & 4,4 \\
\hline
\end{tabular}

SPL 9 dengan nilai SQR 29. Deskripsi kualitas tanah sedang dengan luas kebun 2 ha memiliki produksi 11,2 tons dan produktivitas 5,6 ton/ha. SPL 1, 4, 7, 13, 14 dan 16 dengan nilai SQR berkisar antara 31-40. Deskripsi kualitas tanah buruk dengan luas kebun berkisar 12,5 ha memiliki produksi berkisar dari 3,7-11 tons dan produktivitas 3,7-5,0 ton/ha. Hubungan antara SQR dan produksi kakao di Kabupaten Pidie Jaya disajikan pada Gambar 1 dan 2.

Gambar 1 (a) menunjukan SPL 5 yang memiliki nilai SQR tinggi memiliki produksi yang rendah dan pada SPL 9 dengan nilai SQR rendah memiliki produksi yang tinggi. Hal ini disebabkan nilai SQR menunjukkan banyaknya faktor pembatas, SPL 9 memiliki nilai SQR tinggi karena faktor pembatasnya tergolong sedang dan produksinya termasuk tinggi. Sebaliknya pada SPL 5 yang memiliki nilai SQR tinggi disebabkan faktor pembatasnya tergolong ekstrim sehingga produksinya rendah.

Gambar 4 (b) menunjukan korelasi antara nilai SQR dan produksi ditunjukkan oleh formula: Y $=25,214-0,4806 \mathrm{X}$. Ini bermakna bahwa setiap kenaikan nilai $\mathrm{SQR}=1$, maka produksi akan turun sebesar 0,4806 ton/ha. Korelasi ini menunjukan hubungan negatif (terbalik), bahwa kenaikan nilai SQR menyebabkan produksi turun. Nilai SQR didapatkan dari penambahan bobot faktor-faktor pembatas, dimana semakin tinggi nilai SQR, maka semakin tinggi faktor pembatasnya dan produksi semakin rendah. Sebaliknya jika nilai SQR rendah, maka semakin baik kualitas tanah, sehingga produksi dan produktivitasnya semakin tinggi. 
Soil Quality Rating

Produksi (ton/ha)

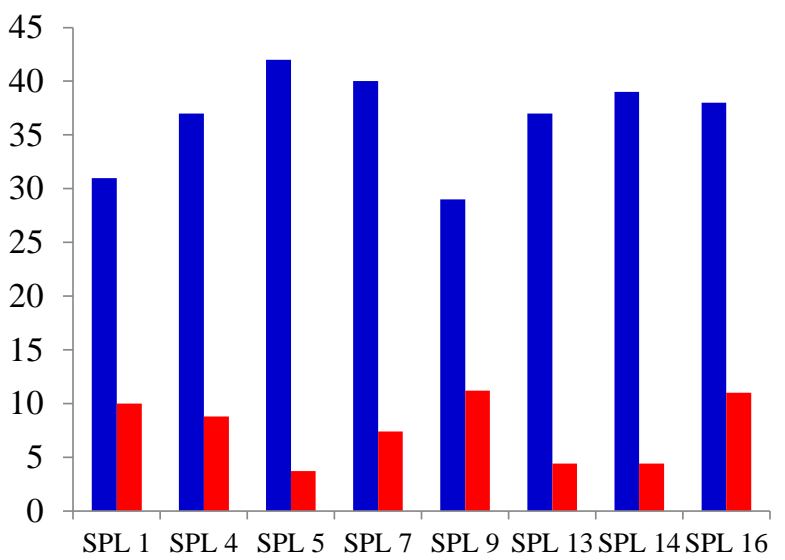

(a)
Produksi

$$
Y=25,214-0,4806 x
$$

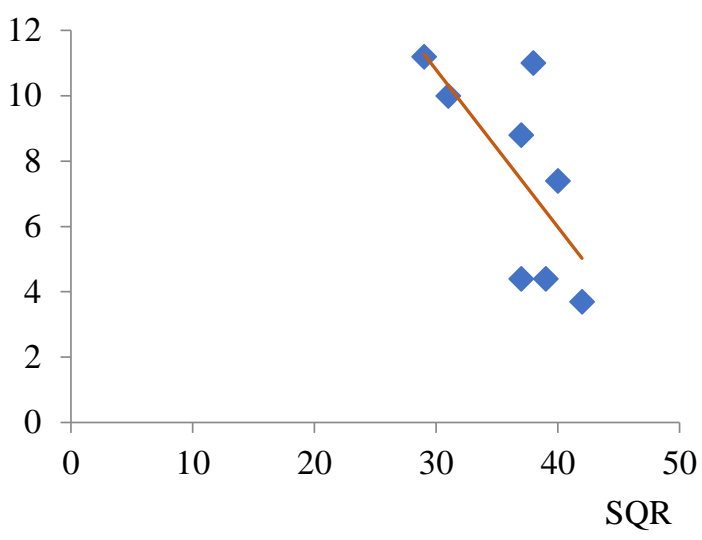

(b)

Keterangan: $\mathrm{Y}=$ produksi (ton/ha); $\mathrm{x}=$ nilai $\mathrm{SQR}$

Gambar 1. Hubungan antara Nilai SQR pada setiap SPL (a); Korelasi antara Nilai SQR (b) dan Produksi Kakao Rakyat di Kabupaten Pidie Jaya

\section{KESIMPULAN}

Kualitas tanah kebun kakao rakyat di Kabupaten Pidie Jaya termasuk kedalam kriteria kualitas tanah sedang, buruk, dan sangat buruk. Produksi kakao rakyat di Kabupaten Pidie Jaya seluruh satuan lahan dalam kategori rendah yaitu 3,7 - 11,2 tons/ha. Bila dikaitkan dengan kualitas tanah, maka produksi kakao relevan dengan kualitas tanah, yang ditunjukan oleh persamaan linier: $\mathrm{Y}=25,214-0,4806 \mathrm{x}$.

\section{DAFTAR PUSTAKA}

Badan Pusat Statistik Pidie Jaya. 2020. Pidie Jaya dalam Angka. Pemerintah Kabupaten Pidie Jaya, Aceh.

Buckman, H.O dan L.D. Brady. 1984. Ilmu Tanah. Braharta Aksara, Jakarta.

Damanik, M., M. B. Effendi., B. Fauzi., Sarifuddin dan H. Hanum. 2010. Kesuburan Tanah dan Pemupukan. Fakultas Pertanian Universitas Sumatera Utara, Medan.

Darmawijaya, I. 1980. Klasifikasi Tanah. Dasar Teori Baru Penelitian Tanah dan Pelaksanaan Pertanian di Indonesia. Balai Penelitian Teh dan Kina Gambung, Bandung.

Das, B.M. 1995. Mekanika Tanah 1. Erlangga, Jakarta.

Doran, J.W., Coleman, D.C., Bezdicek, D.E., and Stewart, B.A. 1994. Defining Soil Quality for a Sustainable Environment. Soil Science Society of America, Madison.

FAO. 1976. A Frame Work for Land Evaluation. FOA Soil Bull. Soil Resources Management and Conservation Service Land and Water Development Division. FAO Soil Buletin NO 52, FAO- UNO, Rome. 
Fitriatin, B. N., A. Yuniarti., T. Turmuktini., dan F. K. Ruswandi. 2014. The Effect of phosphate solubilizing microbe producing growth regulators on soil shosphate, growth and yield of maize and fertilizer efficiency on Ultisol. Eurasian J. of Soil Sci. Vol. 2 No 01

Fiants, D., N. Hakim and EV. Rants. 2005. Properties and Utilisation of Andisol in Indonesia. University of Andalas Limau Manis. Padang.

Foth, H. D.1998. Dasar Dasar Ilmu Tanah. UGM Press, Yogyakarta.

Hardjowigeno, S dan Widiatmaka. 2007. Evaluasi Kesesuaian Lahan dan Perencanaan Tata Guna Lahan. Universitas Gadjah Mada Press, Yogyakarta.

Hanafiah, K.A. 2010. Dasar Dasar Ilmu Tanah. PT Raja Grafindo Persada, Jakarta.

Irfan, M. 2014. Isolasi dan enumerasi bakteri tanah gambut di perkebunan kelapa sawit PT. Tambang Hijau, Kecamatan Tambang, Kabupaten Kampar. Jurnal Agroteknologi. Vol. 5 No, 1 (2014)

Lal, R. 1994. Methods and Guidelines for Assessing Susutainable Use of Soil and Water Resource in The Tropics. Soil Management Support Service USDA Soil Conservation Service, Washington. Vol 5 No 3

Larson, W.E and Pierce, F. J.1994. Conservation and Enhancement of Soil Quality. USDA Natural Resources Conservation Servis, USA.

Hardjowigeno, S. 2003. Ilmu Tanah. Akademi Pressindo, Jakarta.

Liyanda, M., A. Karim., Y. Abubakar. 2012. Analisis Kriteria Kesesuaian Lahan Terhadap Produksi Kakao pada Tiga Klaster Pengembangan di Kabupaten Pidie. Pasca Sarjana Prodi Konservasi Sumberdaya Lahan Universitas Syiah Kuala, Banda Aceh. Jurnal Agrista, Vol 16, No 2.

Susanto, R. 2005. Dasar-Dasar Ilmu Tanah. Kanisius, Jakarta.

Tan, K. H. 1991. Dasar-Dasar Kimia Tanah. UGM Press, Yogyakarta. 